\title{
ENVIRONMENTAL DESIGN AND PLANNING STRATEGIES TO MITIGATE WASTE CONDITION IN NIGHTLIFE ZONES: THE CASE OF REEPERBAHN STREET, HAMBURG, GERMANY
}

\author{
NASIMEH FALLAHRANJBAR, HSIAO-HUI CHEN \& UDO DIETRICH \\ REAP Research Group (Resource Efficiency in Architecture and Planning), \\ HafenCity University Hamburg, Germany
}

\begin{abstract}
Areas with nightlife activities carry high social density and lack of surveillance. Inappropriate waste disposal is one of the negative results triggered by an overcrowded and unorganized public space. This paper aims to propose strategies to improve waste management problems in nightlife areas by investigating Reeperbahn, a touristic area in Hamburg, which sees high volume of plastic cup waste, inappropriate waste disposal, lack of urban furniture and a chaotic sidewalk space. The main research question is how to turn waste collection into a pleasant experience. The proposed strategies were developed in a student's project of the master-program of HafenCity University and address three intervention stages that aim to solve the problem by offering alternative options for the user by changing the structure of the environment: 1) Use identity of the location to create local solutions, e.g. a local deposit system to be introduced to reduce waste generation. It is essential to encourage shopping units, bars and people to join in with this system with incentives such as reusable bioplastic cups with a customized design which will be used within the area and can also be sold as souvenirs. 2) Waste collection as an activity that engages users. Installing innovative and interactive litter bins and trash bins/containers that can engage people in a joyful way to dispose of their waste, such as the successful stories in the Olympic Village in London and Disneyland with walking and talking trash bins. 3) Environmental design recommendations, e.g. implementing design tools such as pavement, coloring code and urban furniture towards creating new structures of environment to encourage proper waste disposal behavior. Improving the waste situation in a nightlife zone requires a holistic approach. This paper intends to contribute to the discussion about the importance of users of a place and the public space features. The future studies may benefit from the local solutions with use of innovative technologies offered in this research.

Keywords: pro-environmental behavior, interactive innovative, conformity, local pfand, bioplastic.
\end{abstract}

\section{INTRODUCTION}

Nightlife zones are popular recreational areas where people escape from daily routine to represent carefree behavior without realizing its consequences. One example of such behavior, inappropriate waste disposal by large amount visitor at night, can bring the area into a chaotic situation and accumulate high amount of waste generation. We propose that the improvement of the waste handling should integrate people into an interactive scenario that engage them to enjoy their time being part of the game and conveying expected behavior at the same time.

Also, the built environment influences the behavior of its users through signals. These signals can be directly sent through warning signs and advertisement. Alternatively, it can be indirectly sent via planned service system and proper set of urban furniture. In the case of Reeperbahn street, the proposed strategies aim to activate user without direct moral message. 

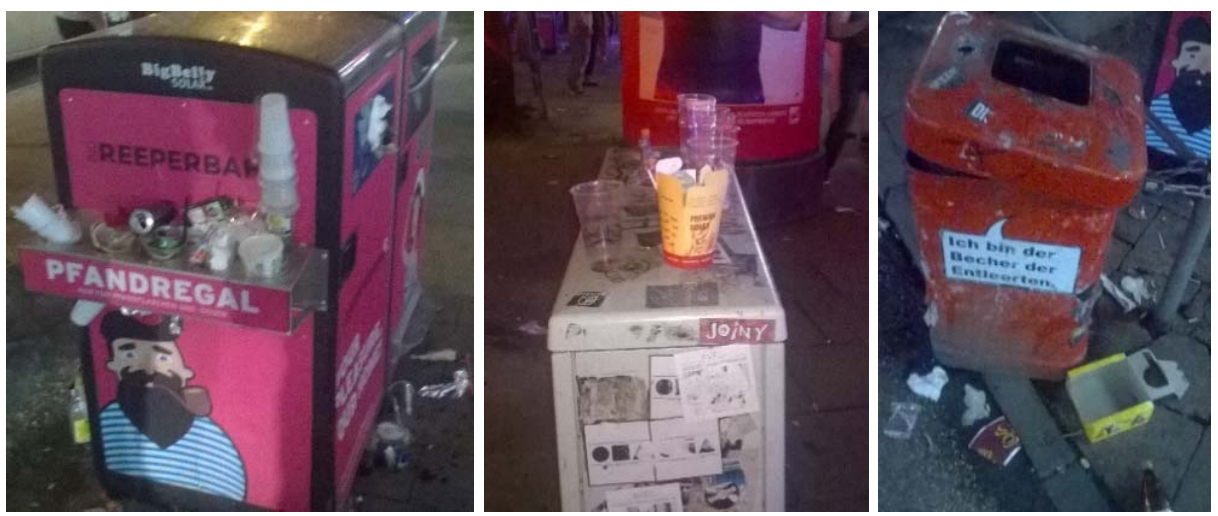

Figure 1: Inappropriate waste disposal in Reeperbahn, Hamburg.

\section{STATE OF ART}

\subsection{General description}

Reeperbahn street is a popular touristic areas of Hamburg that is known for its nightlife activities. There is an influx of tourists within this area. The sidewalk experiences the most crowded times in the summer especially on the weekends. The spatial structure of the street consists of bars and shops facing an empty pathway without any urban furniture and few lighting equipment. The high consumption of food and beverage results into a significant volume of waste products on this street. Therefore, the situation is at a critical stage due to improper waste disposal (see Fig. 1).

\subsection{Observation on a week-end}

In order to collect accurate data from the generated waste on Reeperbahn, a sit survey was carried out using observations on a summer week-end. Ten bins/containers were selected at random. The waste disposed by 10 people were counted according to the amount and type. The initial observations show that the number of trash bins and containers placed on sidewalks seems inadequate. Also it is difficult to distinguish a trash bin on a crowded sidewalk. They are barely visible at night due to their rusty and damaged condition and also the under lit sidewalk. The capacity and the chosen location for trash bins are also questionable. Moreover, there is no sitting furniture on the sidewalks except some private tables in front of bars. Therefore, people may use any box-shaped containers they find (such as elextricity boxes) as dining table and do not clear out the waste as they are finished eating on them. One can witness littering all over the place, for instance in flower boxes and by the trees. Four types of waste were found in the area. The majority being plastic cups and glass bottles, although it is forbidden to sell glass bottle on this street. The transparent plastic cups are used to sell beverages. There are also three main types of bins/containers available (see Table 1).

\subsection{Derivation of improvement strategies}

Huge amount of plastic cup waste, the undesirable condition of rubbish bins/containers and inappropriate waste disposal behavior are the main findings of the observation. Thereupon, 
two main issues should be addressed to improve the excess waste situation in Reeperbahn. The first one is to reduce the plastic cup waste generation and the second one is to amend waste disposal. In the first issue, using non-reusable plastic cups to sell beer and beverage has led to high plastic waste generation. The second issue itself is a result of two conditions, including the choice of bins/containers regardless to the user's needs and characteristics and the sidewalk arrangement that encourages the rush and leaves no place for pro-environmental behavior from users. In the coming sections, the proposed strategies for each part are discussed.

Table 1: Types of generated waste and available bins/containers.

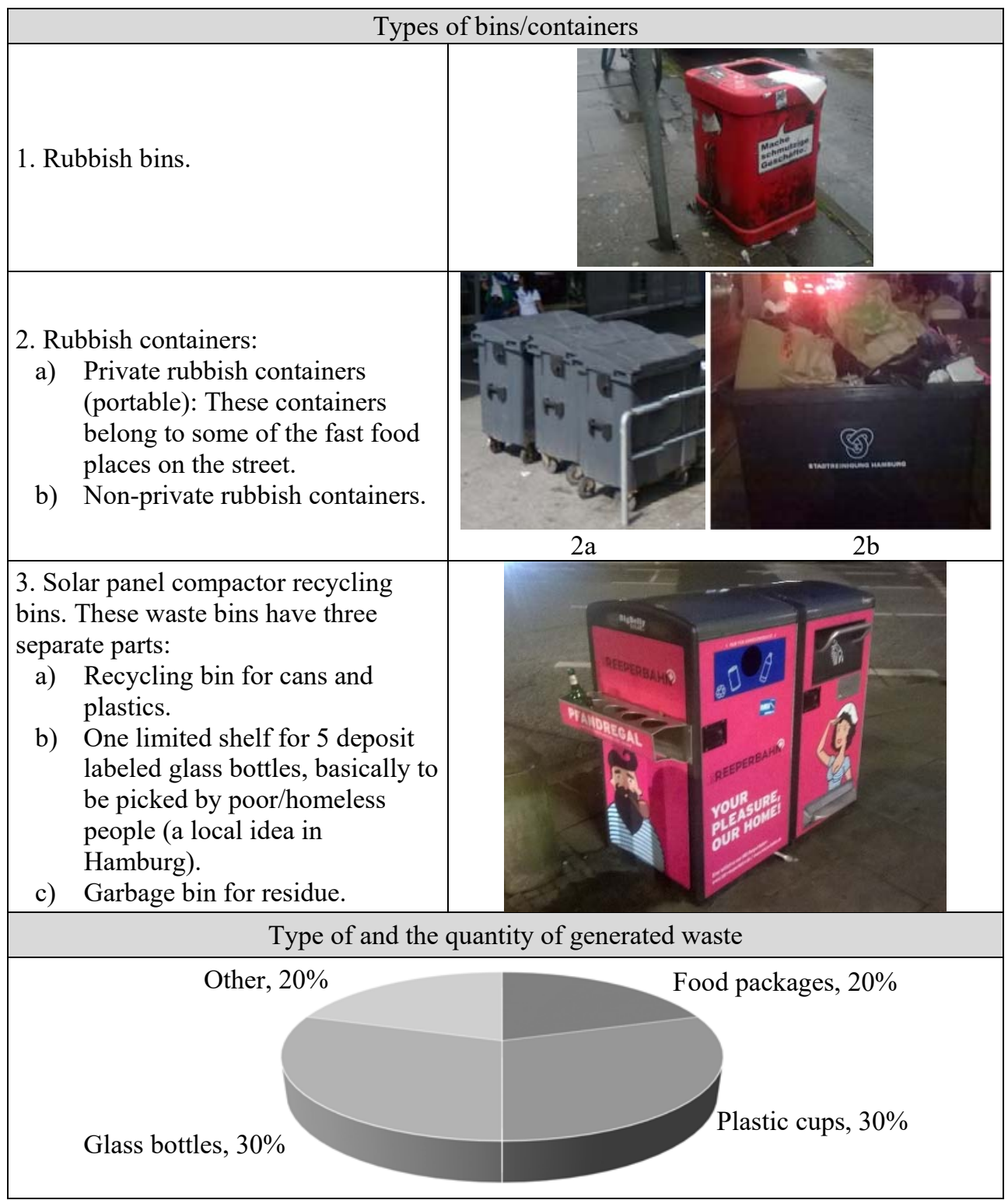




\section{LOCAL PFAND SYSTEM}

\subsection{Pfand system in Germany}

Pfand system is the German deposit system which has been applied in Germany for many years. It is mostly used for glass and plastic bottles and for cans [1]. The term "pfand" refers to the deposit being returned to the costumer when they return the bottle or the can. In special events and temporary markets similar system is applied for cups. The drink is sold with an extra price for pfand and the costumer can only receive the money back by returning the cup to the same selling unit. Night life zones, such as Reeperbahn, are places with regular events with large number of visitors. Implementing pfand system for these areas can help reducing waste from the plastic cups. However, it is necessary to tailor the system into local conditions. One important factor in managing waste disposal in night life zones is to make the process easy and to encourage the people and the selling units to participate. For this reason, a local pfand system for Reeperbahn with some differentiations is proposed.

\subsection{Reeperbahn pfand system}

Reeperbahn pfand system is based on the participation of all bars and kiosks on the street as selling units which sell the customized cup. It begins by providing all selling units with the same cup so that the visitors do not have to return the cup to a specific unit. One significant characteristic of this local pfand system is that, instead of only receiving the deposit, the visitors can choose to receive a token by putting the cup into vending machines available throughout the area. The tokens can be used to buy another drink from the selling units. Another choice is to keep the cup to use next time on the street which would be practical for local visitors. These additional options act as incentives to encourage people to remain in the system. For the ease of access, a number of stands as supplementary selling and collecting units will be added to the area. Since the customized cup is reusable and exclusively designed for Reeperbahn, it can also be sold as souvenir by the stands and vending machines. The process is demonstrated in Fig. 2.

Each selling unit joining this system must deposit its share of cups production cost. They sell beverage using these cups and accept any other dirty cups from customers. A separate place for cleaning is considered within the area. Dirty cups will be collected and delivered to the cleaning area. At the time of delivering clean cups to selling units, balancing recalculations must be done. Balancing is the most important part of this system which can be done monthly or weekly.

Additionally, there will be losses in the system due to general damage or the cups would be sold as souvenir or be kept at home. For this reason, a regular supply of new cups is required. The time to charge the system with new cups depends on the amount of loss and can be flexible from monthly to annual.

This model suggests that the system starts with 10000 cups, 10 selling units and the production fee of $2.50 €$ per cup. An assumption for monthly loss of $10 \%$ of the total stock is considered which has to be replaced monthly. There could be share distribution of $20 \%$ for the tourists and $80 \%$ for visitors from Hamburg (Table 2), mainly because local visitors have less intention to buy the cup. The founder of pfand system in Germany, DPG Deutsche Pfand system $\mathrm{GmbH}$ [1] can be the investor. By investing $25,000 €$ initially and 7,500 $€$ monthly, the system would run. The most important benefit from implementing such system is the reduction of environmental impacts by reducing the number of plastic cup waste, and accordingly bringing back the cleanness to the area. Through tourists the cup would reach 
the world and the joined units would receive more costumers. The improved identity of Reeperbahn would become widespread.

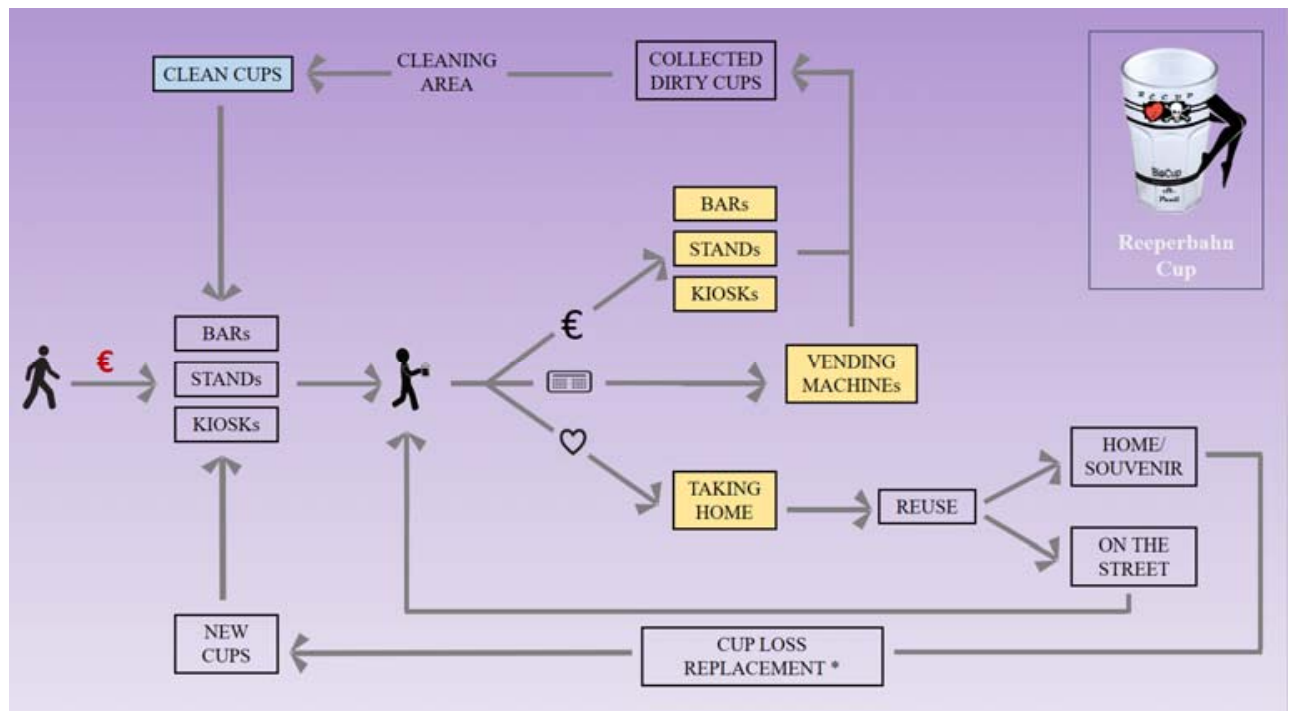

Figure 2: The cup circulation in local pfand system. (*There would be losses in number of cups due to general damage or being sold as souvenir.)

Table 2: An example of a financial model for local pfand system [2]. The system can be started with 10000 cups and 10 selling units.

\begin{tabular}{|c|c|c|}
\hline \multicolumn{3}{|c|}{ Organization financial statements } \\
\hline & Unitary & Monthly statement \\
\hline Selling units & & 10 \\
\hline New cups & 1000 & 1,000 \\
\hline Cups for cleaning & & 1,000 \\
\hline Total cups & & 10,000 \\
\hline Sold cup & $€ 2.7$ & $€ 810$ \\
\hline Investment & & $€ 24,790$ \\
\hline Unitary cost & $€ 2.5$ & $€ 2.5$ \\
\hline Total income (from DPG org.) & & $€ 25,600(100 \%)$ \\
\hline Marginal contribution & & $€ 600(2 \%)$ \\
\hline Total cost & & $€ 25,000(98 \%)$ \\
\hline \multicolumn{3}{|c|}{ Administrative Expenses } \\
\hline & Unitary & Monthly statement \\
\hline Cleaning $€ /$ cup & $€ 0.02$ & $€ 200$ \\
\hline Collecting $€ /$ unit & $€ 10$ & $€ 100$ \\
\hline Administrative fee & $€ 300$ & $€ 300$ \\
\hline Total expenses & & $€ 600(2 \%)$ \\
\hline Utility break even point & & $0 \%$ \\
\hline
\end{tabular}




\subsection{Reeperbahn cup}

Reeperbahn cup is a reusable transparent plastic cup preferably made of bioplastic. It is understood that bioplastics have low impact on environment, since less greenhouse emission occurs during their lifetime. However, they require extensive land use, they are relatively expensive and would turn into compost only under high temperature and special circumstances. There are basically two types of bioplastics. One is PLA made from sugars in corn starch and the other is PHA made by microorganisms, while traditional plastics are made from petroleum-based raw materials [3]. For the highest efficiency, it is better to use bioplastic produced by renewable sources of energy. Bioplastic products such as bioplastic cups are available in today's market and the technology is progressing rapidly. Apart from the material, an exclusive design for cups is recommended that carries the identification of the street. The design of the cup is illustrated on the top-right corner in Fig. 3. The cups could even be personalized with a first name of customer in selling units.

All of the ideas behind local pfand system and the cup is to act as motivators for visitors to become active parts in reducing the generation of plastic cup waste. Although it is possible that the visitors may forget their cups on the street, this system may motivate the poor or the homeless people to collect pfand bottles and cans so that the number of the Reeperbahn cup left on the street can be reduced. In this way even the poor and the homeless people can be indirectly included in the system.

\section{IMPROVED BINS}

There are two methods of waste collection on public spaces after and during the event. The first one is normally done by municipality and responsible organizations. The second one, which can be considered as a passive method, is done by people participating in the event. In this manner, the more the space users are engaged, the cleaner the area would be and everyone would have a better experience of the event.

As previously mentioned, people refuse to use bins/containers properly in Reeperbahn, mainly due to rusty and filthy condition of rubbish bins/containers. This means that different design features in term of color, material, shape and working mechanism are needed for Reeperbahn's rubbish bins/containers. People should be encouraged to use rubbish bins/ containers and the act of waste disposal should be interesting and funny as it is a part of the game. Interactive innovative technologies for rubbish bins/containers that support social interaction are the best means to encourage people to have a proper waste disposal and show a pro-environmental behavior. As conformity influences behaviors, people follow the behavior of the group they belong to. After few people start to use the technology, others may also follow.

\subsection{Successful examples}

New technologies and ideas have been recently brought into recycling bin designs. The concept is to give the recycling a higher profile in the community and make it fun and easy. Some of these technologies are designed to encourage people to use the bins in public open spaces which get crowded at night. TetraBIN [4] is one of these technologies used in Sydney lighting festival 2014. See Fig. 3 as an example. It uses LED panels to light up the filled part of the bin and creates a game inviting people to fill the bin. This attractive bin helps promoting sustainable behavior and creates a playful experience, especially for children [4].

Another technology is a reverse vending machines that pays recyclers. PepsiCO Dream Machine [5], as shown in Fig. 4(a), was installed in popular public venues such as gas 
stations, stadiums and parks in US. It gives the use points and prizes in exchange for an empty bottle or can. The concept is to encourage recycling when people are away from home, with no access to a convenient recycling bin [5]. Another innovative idea is applied to a litter bin design to motivate people to make disposing of litter in a joyful manner. Farrier [6], an environmental charity in the UK, created a series of urban trash cans where people can vote with their cigarette butts for whom they think is the greatest soccer player in the world: Lionel Messi or Cristiano Ronaldo [6]. See Fig. 4(b) as an example. Regarding zero waste concept, same color codes were used for both trash bins and food packages in London Olympic Games in 2012 to make the recycling easier [7]. See Fig. 4(c) for the example.

Underground containers are designed to save space. Large containers will be installed under the ground and on the top the rubbish bin is set for waste disposal (see Fig. 5(a) and 5(b) as the example). Saving space is the most impportant concept in this example.

Yet another example would be to use the bio polymer gel to create a recycling rubbish bin. As shown in Fig. 5(c), one can easily put any thing into this gel without opening the door. The technology is currently used to create future generation of refrigrators.

\subsection{Design criteria for trash bins}

The main idea in collecting design criteria for trash bins is to actively include visitors in the process of waste collection and make the process of waste disposal pleasant. According to
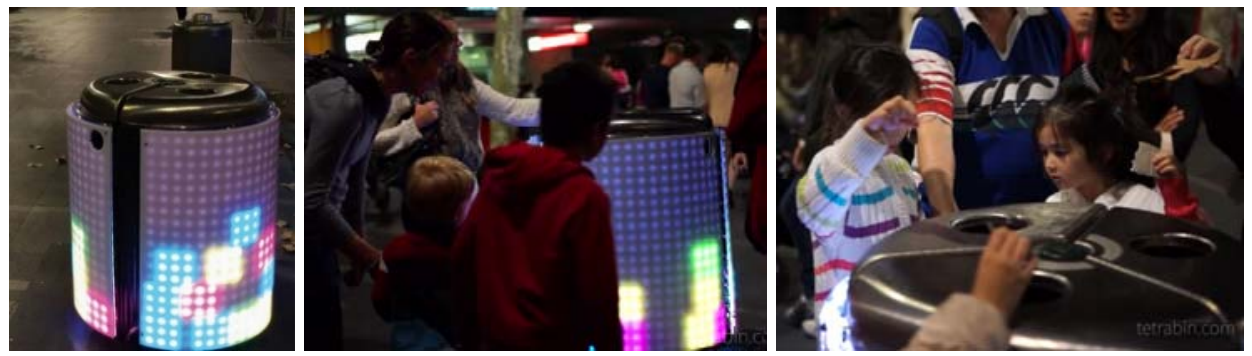

Figure 3: TetraBIN, lightening trash bin [4].
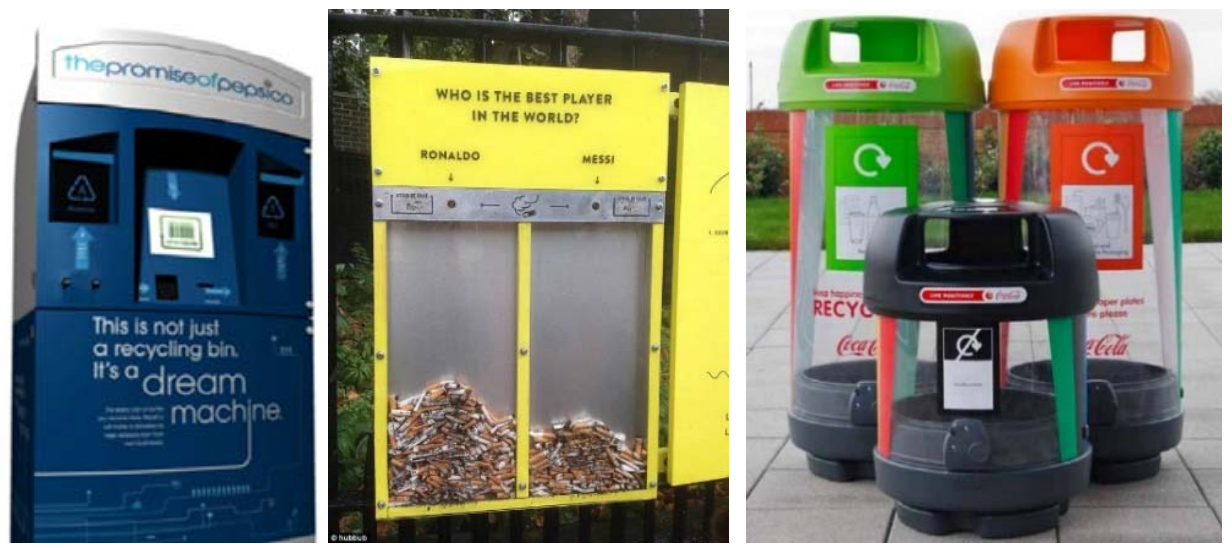

Figure 4: From left (a) PepsiCO dream machine [5]; (b) Hubbub interactive litter bin [6];

(c) Recycling bins with color code [7]. 

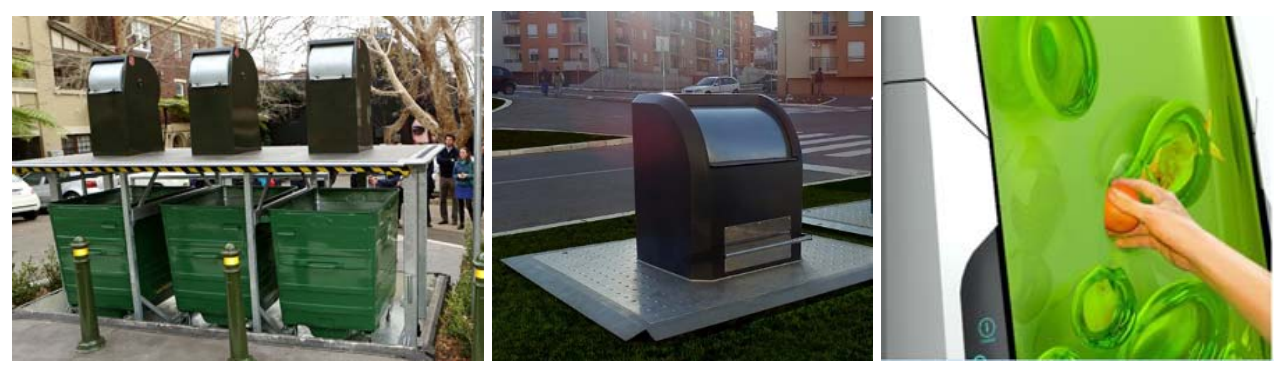

Figure 5: $\quad$ From left (a) Underground wast trail [8]; (b) underground containers [9]; (c) Future refrigrator with biopolymer gel [10].

site observation report and successful examples, four types of rubbish bins/containers are recommended for the street of Reeperbahn:

1. PV compactor Big Belly containers (with 2-3 sections for recycling); every 60 meters.

2. Underground containers; in front of chain fast-food restaurants.

3. Small rubbish bins for residue; every 20 meters between BigBelly containers.

4. Interactive litter bins for cigarette butt; at the entrance of train stations and bars.

These 4 different types of rubbish bins/containers should be exclusively designed for Reeperbahn street. The design of these bins/containers should follow a set of regulations for physical aspects to optimize their function according to Reeperbahn street:

a) Shape:

- Attracting attention: to encourage people to use bins/containers.

- Capped containers: to avoid the smell, wasps and the view of trash.

- Pedal system: to avoid usage of hand and to ease the disposal.

b) Material:
- Durable with high quality.
- Bright and shining colors.
○ Lightening segments.

c) Other:

These features can only be considered for 1-2 number of bins/containers.

\author{
- Shade. \\ - Sitting part. \\ - Camera (take fun picture of users), Wi-Fi, charging port.
}

The locations of these rubbish bins should not overlap and should be located off the sidewalk. An example of the proposed new set of arrangement is shown in Fig. 6. 


\section{ENVIRONMENTAL DESIGN}

One reason for seeing the rusty bins in Reeperbahn is the vandalism due to lack of surveillance in the area. The environmental characteristics can promote or prevent vandalism. Experience shows that people behave differently from one environment to another, depending on the structure and characteristics of the area [11]. Sidewalks of Reeperbahn are indeed a public space with minimum social interaction. On events and during night hours on the weekends a huge crowd is moving along the sidewalks to access the bars or restaurants leaving no space to stand or to sit. In this situation when people are in hurry, no social interaction and no perceived surveillance can occur. Eventually, people's respond to the environment will not be towards preserving the place. We propose to change the environment to make the behavior more convenient for social interaction so that people can be more aware of their waste disposal behavior [12].

As an interventional approach to change environmental structure in order to refurbish the area, an open space in front of a crowded chain restaurant was selected (Fig. 7). The aim is to create more space for pedestrians and to promote social interactions. For these reasons, the existing rubbish containers where replaced with underground containers and a set of urban furniture consisting of siting area, shading and lighting were added. The results are displayed in Fig. 8.

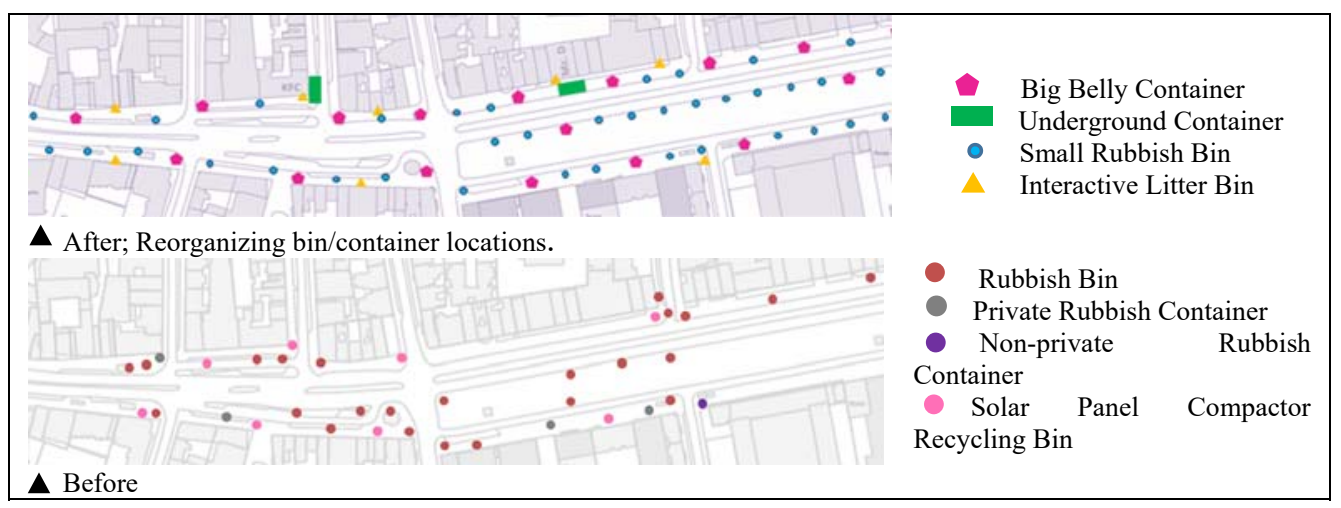

Figure 6: Bins/containers location on map, before and after.
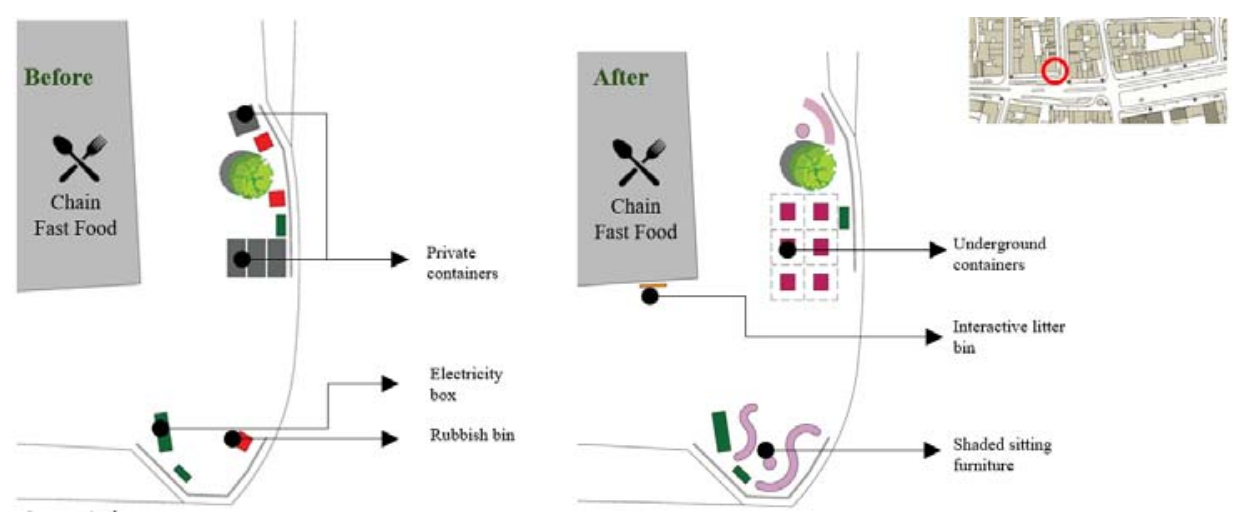

Figure 7: An example of renovative design on sidewalk, before and after. 

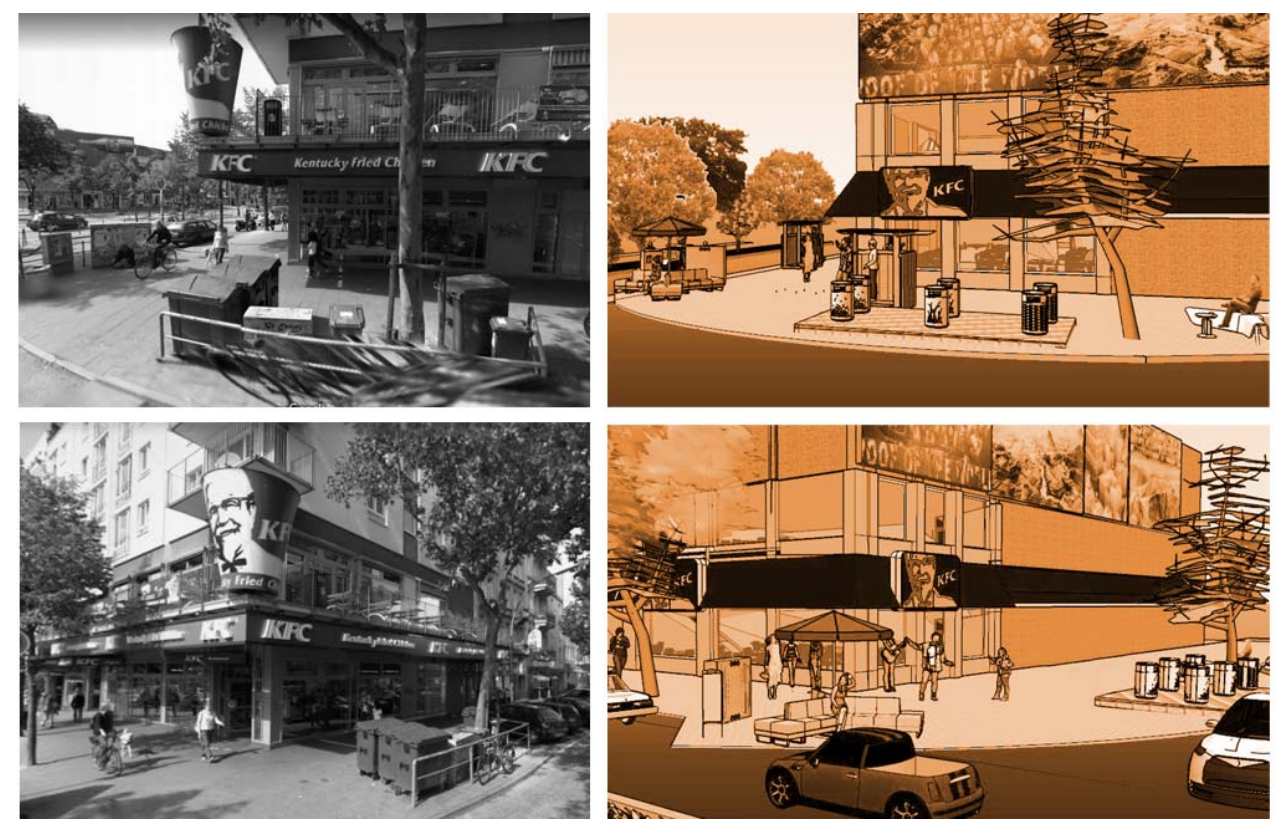

Figure 8: Current photos compared to 3D model views of renovative design on sidewalk.

\subsection{Design recommendations}

The following factors are recommended to be considered when renovating a night life zone regarding waste disposal.

- Choose bin/container technology according to the available space.

- Use color codes with sharp and luminous colors on pavement to connect bins/containers visually and make them easier to find.

- Create set of urban furniture including all necessary equipment.

○ Choose bench's design and arrangement that encourages social interaction.

\section{CONCLUSION}

Issue of waste in nightlife zone is essentially related to visitors' behavior. Therefore, our approach emphasize that the visitors should be actively integrated in waste management process. How can we turn waste collection into a pleasant experience? Our proposal deals with both environmental structure and social behavior. Recognizing user's needs and considering local situation are the key factors in both approaches. Environmental design regarding psychology-based interventions is a powerful mean to tailor waste issue in public spaces. Providing various equipment in the area that encourage people to participate in waste disposal while interacting with each other in groups provokes the sustainable behavior within the entire area. Improving waste situation in a nightlife zone requires a holistic approach. This paper intends to contribute to the discussion about the importance of users of a place and the public space features. The future studies may benefit from the local solutions with use of innovative technologies offered in this research. 


\section{ACKNOWLEDGEMENT}

This study was made possible through efforts from my colleagues in project group of REAP master program of HafenCity University; Maria Tadarova and Amir Mohamad Alinaghian.

\section{REFERENCES}

[1] DPG Deutsche Pfandsystem GmbH, Function of the Deposit-Scheme. http://dpgpfandsystem.de/index.php/en/. Accessed on: 17 Feb. 2018.

[2] Garcia, L., Calculation of financial model, 2018.

[3] Cho, R., The truth about bioplastics. https://phys.org/news/2017-12-truthbioplastics.html. Accessed on: 17 Feb. 2018.

[4] Murano, 10 Creative Ideas to Reduce Littering \& Vandalism. https://www.oddee. com/item_99512.aspx. Accessed on: 20 Jul. 2017.

[5] Starr, G., PepsiCo Dream Machine ${ }^{\circledR}$ Recycling Initiative. http://www.pepsico.com/ live/pressrelease/pepsico-dream-machine-recycling-initiative-presents-500000-tothe-entrepreneursh03072013. Accessed on: 20 Jul. 2017.

[6] Farrier, J., Clever Trash Cans Reduce Littering. http://www.neatorama.com/ 2015/09/16/Clever-Trash-Cans-Reduce-Littering/. Accessed on: 20 Jul.2017.

[7] Pratt industries, Zero-Waste: An Olympic-Sized Mission. http://innovations. prattindustries.com/2012/08/08/zero-waste-an-olympic-sized-mission/. Accessed on: 12 Jan. 2018.

[8] City of Sydney, A Unique Place-Based Solution, http://www.cityofsydney.nsw.gov. $\mathrm{au} /$ vision/better-infrastructure/buildings-and-facilities/completed/underground-wastetrial. Accessed on: 20 Jul. 2017.

[9] Ecosignal, Why Underground Containers? http://www.ecosignal.eu/index.php?id=22. Accessed on: 20 Jul. 2017.

[10] Liggett, B., Zero-energy Bio Refrigerator Cools your Food with Future Gel. https://inhabitat.com/zero-energy-bio-refrigerator-cools-your-food-with-future-gel/. Accessed on: 12 Jan. 2018.

[11] Newman, O., Creating Defensible Space. https://www.huduser.gov/publications/ pdf/def.pdf. Accessed on: 12 Jan. 2018.

[12] Sussman, R. \& Chikumbo, M., Behavior Change Programs: Status and Impact. http://www.ourenergypolicy.org/wp-content/uploads/2016/10/b1601.pdf. Accessed on: 17 Feb. 2018. 